\title{
Regulation needs new legislation to get lighter
}

\author{
Author: Terence Stephenson
}

The General Medical Council (GMC) has been regulating doctors since 1858 and our purpose is clear: we protect the public by deciding which doctors practise in the UK, set standards that doctors must follow throughout their careers and take action to prevent doctors putting the safety of patients or public confidence at risk.

The GMC was originally set up by Act of Parliament in 1858 to help the public tell a qualified doctor from a quack. Modern healthcare is more complex than that. Demands on professionals and the health system have changed dramatically and we cannot stand still. We need to keep examining our role so that regulation remains relevant.

We know that the vast majority of doctors are hard-working professionals doing an exceptional job in often difficult circumstances. Very few have action taken against them under our fitness to practise procedures - there are 267,000 doctors on our register and less than 100 doctors are struck off each year. Our main interest is in supporting improvement and that means moving upstream to support good practice for the majority, not just fishing downstream for the minority who find themselves in our fitness to practise procedures.

That's why our work in education and training, standard setting and revalidation are really the heart of what we should be doing. It makes regulation relevant to far more professionals than will ever engage with our fitness to practise processes.

If our job is to protect patients from harm and support the profession to be good doctors, then it doesn't make sense to be spending most of our time dealing with fitness to practise issues where harm has already happened. Nor should we underestimate the impact that fitness to practise procedures have on doctors themselves and their confidence in regulation, regardless of the outcome.

That's not to say we shouldn't take action when things go wrong. But if most of our resources are directed towards that, it becomes more difficult to work constructively with the majority of doctors to support good practice and improvement. The more we can shift regulation upstream, the better we can promote good practice and potentially limit harm downstream.

We are moving in the right direction. In 2010, we introduced our Employer Liaison Service to engage with responsible

Author: chair, General Medical Council, London, UK officers and share information better. We've established our Doctor Support Service for those doctors going through fitness to practise processes and piloted provisional enquiries, closing down cases more quickly and reducing the number of full investigations we carry out. We would like to introduce this for single clinical incidents, reducing further the time and stress expended on investigations that could be dealt with locally.

But to make further reforms we need new legislation to make regulation more agile. Our current legislation was introduced when the GMC saw just a few hundred cases per year - we now receive around 9,000 complaints each year.

With legislative reform we could reduce unnecessary investigations, decrease stress on doctors, better manage the expectations of complainants and reduce fitness to practise costs. We also want to speed up the process when it is necessary to go to a hearing. At present, we cannot restrict a doctor's practice by issuing the most severe sanctions, like suspension or erasure, without holding a public hearing - even when a doctor accepts what has happened and is willing to accept the sanction. Our job is to protect the public, not punish doctors, and hearings should only be used to resolve disputes over evidence.

If we're serious about regulating further upstream we need a more proportionate suite of regulatory sanctions for addressing concerns about medical education. The power to remove all trainees from a trust or withdraw recognition of a medical school is like taking a hammer to a nut. A more nuanced and escalating suite of sanctions would help us to take decisive action earlier and avoid the need for nuclear options later on.

The legislation underpinning our work is now 30 years old. We understand that the government will consult on the future of professional regulation early in 2017 - this can't come soon enough. Clunky, legally driven processes slow us down and pile unnecessary stress on doctors and their patients. We need new legislation to bring medical regulation into the 21st century.

\section{Conflicts of interest}

Professor Terence Stephenson is chair of the General Medical Council and a practising consultant paediatrician.

Address for correspondence: Prof Terence Stephenson, General Medical Council, 350 Euston Road, London NW1 3JN, UK. Email: Terence.stephenson@gmc-uk.org 